\title{
The Discussion of Teaching Effection about Combination of Architectural Graphing and CAD
}

\author{
$\mathrm{Hu} \mathrm{Yu}$, Zhang Ming \\ Dept. of Civil Engineering, Henan Institute of Engineering, Zhengzhou, China
}

\begin{abstract}
Architectural graphing and CAD are two important specialty basic courses to those students of Civil Engineering. In this paper, teaching method, tools, effection and interaction are analyzed and the question which teachers meet in operation and their hard work are discussed in detail. In addition, it is also discussed in this paper that how to bind them together and make teachers express the advantage, then, students can accept it with pleasure.
\end{abstract}

Index Terms: Architectural graphing; CAD; Specialty basic courses

(C) 2012 Published by MECS Publisher. Selection and/or peer review under responsibility of the International Conference on E-Business System and Education Technology

\section{Introduction}

The students of Civil Engineering should understand architectural graph and draw it with AutoCAD(Automatical Computer Aided Design) at now. Architectural graphing is a specialty basic course that study reading and drawing graph among many courses. It mainly study theory and method of drawing and reading engineering graph which is based on descriptive geometry, including basic knowledge and skill of drawing, konwledge of projection and reading graph. The aim and task is learning theory of projection, mastering basic knowledge and method of reading and drawing, training space imagination of students. AutoCAD is a pop drawing software which can rise up student's drawing ability as a basic course and imagine ability and invent ability as an important course. The main purpose of it is how to draw graph with orders. So it can make progress of graph and effiency. It can complete many complex graph which can't be drawn by hand. Alougth CAD has been replaced the hand drawing method, but the drawing theory and standard is still play a great part in this field. On the contrary, the drawing standard of CAD has been

added recently. We have to combine architectural graphing and CAD in order to make students grasp the skill of computer drawing ineffiency[1].

AutoCAD has been taught in many universities now. Teachers can be familiar with function of CAD and use all kinds of orders skillfuly. So the teachers can improve their computer graphical level. Computer graphic is one part of engineer graphics. Many universities either adopt the teaching of integration, or adopt the teaching of phase. In the computer graphic, students can understand the function of AutoCAD and be interested in

* Corresponding author.

E-mail address: honest-2003@126.com,huyu007@gmail.com 
computer graphic with the aid of AutoCAD whether it adopt that kind of teaching.

\section{Analysis}

Every student wants to draw graphic with CAD skillful. It is necessary for them to grasp graphic. During the course of learning gaphic, teaching method is very important for them. Many teachers impart knowledge with traditional teaching method which use drawing tools on the blackboard. It take students much time to complete complex drawings because of the inefficient traditional teaching method. The simple content is not enough vivid or intuitive. It is hard to combine the content of graphic and CAD because of their independent. Firstly, as the basic knowledge of graphic and projection is start of this course and the part of figure is easy, it can be taught on the blackboard. It's necessary for students to get guidance and inspiration with the interest through detail explain on the blackboard. Secondly, there are some pargraph which require strong spatial thinking in the field of multimedia. Such as projection and axonometric drawing of planar object, projection of combination solid, and representation method of architectural form. We can show drawings to students with multimedia courseware. The most difficulty of teaching is the projection of intersection of solids which transform graphic from two-dimension to three-dimension. At the same time, we can observe intersection of solids with multi angle and show it 3-dimension function of CAD. The Interface of CAD will be divided into 4 views which reveal stereogram, main view, left view and top view. Students can make progress of speical knowledge through comparison of two-dimension and three-dimension. Thirdly, some graphics which have close relationship with civil and engineering are belong to architecture graphic. Such as construction graphic and structural working drawing. The large number of graphics reveal the most advanced technique which has been put into use. Teachers can teach students with whole graphic through the CAD. Students will be interested in it because of the engineering cases. Furthmore, we can teach how to use signal with CAD in order to skewer knowledge. Moreover, the most important factor of CAD is aim of practice. Students must draw graphics with CAD in front of computer. There are two weeks for the students to exerise their CAD on the computer. All factors which we have mentioned can be seen in table I.The students' operating level will be changed from quantitative to qualitative. Also, they will have great confidence through drawing graphic idependent and stable foundation for the next work[2] [3][4].

TABLE I. Comparison of Different Teaching Method

\begin{tabular}{|c|c|c|c|c|}
\hline Method & $\begin{array}{c}\text { Trsditional } \\
\text { Teaching }\end{array}$ & $\begin{array}{c}\text { Multi-media } \\
\text { Teaching }\end{array}$ & $\begin{array}{c}\text { Engineering } \\
\text { case }\end{array}$ & $\begin{array}{c}\text { Practice } \\
\text { Teaching }\end{array}$ \\
\hline Tools & $\begin{array}{c}\text { Blackboard, } \\
\text { Triangle } \\
\text { plate, } \\
\text { Compasses }\end{array}$ & $\begin{array}{c}\text { Computer, } \\
\text { Software of } \\
\text { CAD, } \\
\text { Projector }\end{array}$ & $\begin{array}{c}\text { Computer, } \\
\text { Software of } \\
\text { CAD, } \\
\text { Projector }\end{array}$ & $\begin{array}{c}\text { Computer, } \\
\text { Software } \\
\text { of CAD, }\end{array}$ \\
\hline Effection & low & good & better & best \\
\hline Interaction & poor & good & better & good \\
\hline
\end{tabular}

\section{Discussion}

During the course of traditional instruction and CAI(Computer Aided Instruction), many problems have been discovered by teachers. We cannot promote students study interesting and improve teaching effect without fully realizing the problems and its dangerous[5]. The problems are as follows:

\section{A. Teaching site.}

In traditional, students always learn CAD in the multimedia classroom. It is proved that the teaching method which teachers show it in front of blackboard and students look on it on the seat has not high efficiency. 
Because CAD needs much time to practice, so it can lead to that result without question. The teachers who have grasped drawing skills can achieve ideal result with moving mouse lightly. But it is difficult for those students who never used software to draw graph. In addition, teachers maybe draw it with shortcut or keyboard in opeartion. Those operation will not be discovered by students at all. In ordinary, students will forget their knowledge very soon if they have not enough time to exerise on the computer in time. So we should have class in the computer room during the course of CAD course. Each student has one computer and teacher divides the konwledge into many steps, so teacher can adjust students' speed according to their completing one step and checked by them. Only in this way can students keep up with teaching content and solve any difficulies. So this teaching method has been received high praise by students.

\section{B. Course teaching method.}

We can combin computer graphic techinque of CAD and specialty course according to theory and features of CAD and different levels of undergraduate ability culture. With systematic introduction of theory and method of drawing and reading architecture, construction, furnishment graphic by computer, the ability which students can complete graphic with typical CAD system of computer will be cultivated step by step. We can instruct students with a series of graphs of actual engineering, such as a whole architecture graph, construction graph, and electric graph,etc. It can not only improve students ability of reading and drawing graph, but also confirm their aims and needs. At the same time, they can solve their many problems in reality. Through those actual engineering, students can grasp the method of using software and solve actual problems in the drawing time. Students have been more interested in study drawing skill of CAD and strengthen their self study ability with this kind of teaching method.

\section{Emphasis on basis.}

Grasping basic knowledge of CAD is emphasised on teaching, so the operating skills will be rased gradualy. With the rapid development of CAD software, upgrade software will be put into use every 2 years. We cannot teach all kinds of CAD for those students. So the actual and core content should be taught in class and students should have more imagination and go over it frequently. We can find the appearance from those graduate students that they are lack of necessary operating skill and rely on the using of specialty software very much. At last, their design thinking is tied in serious. So we must have emphasis on the importance of CAD basic knowledge in the course of teaching. Students will know about the relation of basic software and professional software in depth. Furthmore, we can also make students understand the fact that basic knowledge of CAD can make up defect of professional software and the importance of improving operating skills.

\section{Reform of test.}

Traditional looming test and written test is a simple assement measure but inadequate of CAD test. For example, whether students completeing course design in some phases or students are tested online, their application levels of those softwares will be tested clearly. Examination without paper is prime choice of computer test at present. It can not only test students' ability which they operating all kinds of softwares, but also improve whole quality of students. Nowdays, the education manner is being transformed from examination education to quality education. It is obvious that technical education and application education are fit for it. The system of examination without paper has large numbers of item bank which has a wide range and involving all aspects of course. It can avoid students paying attention to study of part konwledge and strength fully understanding of course. Each paper which is completed by student can reflect the real level of him.

Above all, there are many aspects should be emphasised on the course of using CAD in the future. We should pay attention to:

a) Strengthen construction of teaching software, item bank and network teaching. Firstly, we should improve multimedia teaching plan of course and develop network courseware and item bank. Secondly, we should advise university to strengthen construction of computer hardware because many students can not operate 
but understand it clearly. Every student wants to have class in the multimedia room which has multimedia projection screen and enough computers. So they can operate it on site and improve their drawing speed.

b) Strengthen study of graph standard: Architectural design has been applied computer very early. Computer technique has been achieved rapid development in recent 20 years, so computer technique has been filled with all aspects of architectural design. Architectural and computer technique is not belong to the same subject. The crossing of two subjects is six standards which are promulgated by government. Building Drawing Unified Standard (GB/T 50001-2001) is general programme in the standards. It has been ruled the drawing width, line width, linetype, and text style, label style and pattern filling. So we should obey the rules and standards when we are drawing graph.

c) Flexible teaching should be put into use. Many students maybe lost interested in CAD because of uninteresting orders and operations. If that thing happened, then ti is hard to cultivate students interesting for CAD. Afterward, they cannot study it initiative and positive. It is clear that this effect is not good at all. On the second stage of study, it is uneasy for students to applying konwledge flexiblity because of their unstable basis. Teachers cannot repeat knowledge which has been taught on the first stage because of inadequate time. In the end, the course aims cannot be completed very well. So it is advised for us to take different scheduls according to the different professions.

\section{IV. Conclusion}

In a word, teacher should know about students' study and control teaching schedules reasonable in time. The questions which existed in teaching should be discussed, explained and evaluated on time. Also, hard task will be given students who have enough time to study further. Teachers should instruct those students who are hard to complete their study individually. The members will check teaching task and help each other in order to develop equipment. The mainly purpose of CAD course is operated computer by students. We should analyze the relation element and cultivate their interest to improve students' positive and ability of self study and invention.

\section{References}

[1] Bai Tuya., Ji Lifeng, Ji Zhonghou. Discussion about Combination of Architectural Graphing and CAD. Chemical Industry and Petroleum of NeiMenggu.[J]. 2008.15. (in Chinese)

[2] Ye Aiyin. Discovery of Architectural Graphing and CAD Reform. NeiJiang Science and Technology.[J] 2008.7.(in Chinese)

[3] Jiao Yonghe. The Survey and Development China Present College Graph Teching.[J] Engineering and Graphing Journal. 2002, (5): 160-165.(in Chinese)

[4] Yang Shengqiang. Modern Graphing[M]. Beijing: National Defense Industry Press, 2001.(in Chinese)

[5] Liu Xiaofeng. Teaching Practise Discussion of CAD. Science and Technology Information.[J] 2009.13:512. (in Chinese) 